\title{
An autopsy-confirmed case of progressive supranuclear palsy with predominant postural instability
}

\author{
Carolin Kurz ${ }^{1 *}$, Georg Ebersbach², Gesine Respondek ${ }^{3,4}$, Armin Giese ${ }^{5}$, Thomas Arzberger ${ }^{1,4,5+}$ \\ and Günter Ulrich Höglinger ${ }^{3,4+}$
}

\begin{abstract}
Postural instability and supranuclear gaze palsy represent the key symptoms of Richardson's syndrome, the most frequent clinical manifestation of progressive supranuclear palsy (PSP). However, a proportion of PSP patients never develops ocular motor symptoms, which prevents clinicians from establishing the diagnosis during lifetime according to current diagnostic criteria. We present one instructive autopsy-confirmed PSP case with prospective video-documented clinical course, showing striking temporal divergence of initially present postural instability and delayed development of ocular motor dysfunction. Brain imaging and autopsy findings were typical of PSP, but the temporal sequence of symptoms was unusual with isolated postural instability predominating the clinical course for many years and slowing of vertical saccades/supranuclear gaze palsy evolving not until the $9^{\text {th }} / 11^{\text {th }}$ year after disease onset. Although other differential diagnoses were unlikely, this patient did not pass the threshold for possible or probable diagnosis of PSP according to current diagnostic criteria until very late in the disease course. This first well documented, autopsy confirmed case of PSP with predominant postural instability further expands the clinical spectrum of PSP and points out the need of new clinical diagnostic criteria with sufficient sensitivity and specificity for an early and reliable diagnosis.
\end{abstract}

Keywords: Progressive supranuclear palsy, Atypical clinical phenotype, Postural instability, Neuropathology, Magnetic resonance tomography

\section{Background}

Progressive supranuclear palsy (PSP) is a disease entity defined neuropathologically by aggregates of the microtubule associated protein tau in astrocytes (tufted astrocytes), neurons (neurofibrillary tangles) and oligodendrocytes (coiled bodies) in typical anatomical distribution $[1,2]$. Postural instability (PI) with falls, and slow vertical saccades followed by supranuclear gaze palsy (SNGP) represent the key symptoms of the typical clinical manifestation of PSP - termed Richardson's syndrome (PSP-RS) $[3,4]$. The NINDS-SPSP criteria for the clinical diagnosis of PSP require a combination of PI during the first year

\footnotetext{
* Correspondence: Carolin.kurz@med.uni-muenchen.de

${ }^{\dagger}$ Equal contributors

${ }^{1}$ Psychiatric Clinic, Psychiatrische Klinik, Ludwigs-Maximilians-Universität München, Nußbaumstr. 7, 80336 Munich, Germany

Full list of author information is available at the end of the article
}

and slowing of saccades or SNGP [5]. Proportions of 9-59\% of autopsy confirmed PSP patients have been reported to never develop SNGP throughout the disease course [3, 6-9]. The causes for these variable and high numbers remain unclear. Atypical clinical manifestations of PSP have been described, e.g. PSP with initially predominant Parkinsonism (PSP-P), frontotemporal dysfunction (PSP-FTD), or akinesia with gait freezing (PSP-PAGF), in which SNGP may indeed evolve later in the disease course [10]. A recent retrospective study of $N=100$ autopsy confirmed cases has also suggested that as many as $18 \%$ of PSP patients may have an abortive development of PSP-RS, with PI predominating the early clinical course and SNGP only developing with major delay, coining the term PSP-PI. The existence of PSP-PI cases has been questioned, however, since an apparent lack of SNGP in retrospective series might result from insufficient examination or 
documentation of the actual clinical symptoms. Here, we report the first prospectively video-documented patient with progressive PI predominating the clinical course for many years and very late onset of SNGP, having confirmed PSP at autopsy, supporting the concept of PSP-PI. This patient did not pass the threshold for possible or probable PSP according to current diagnostic criteria until very late in the disease course [11].

\section{Case presentation}

The temporal evolution of symptoms is shown in Fig. 1a and in the supplementary video (Additional file 1). At 67 years of age (in 1997), the initial symptoms occurred: PI, pain of the left shoulder, hypokinesia of the left arm, hypomimia and dysarthria. In the early disease course the gait was minimally affected, it was slightly broad

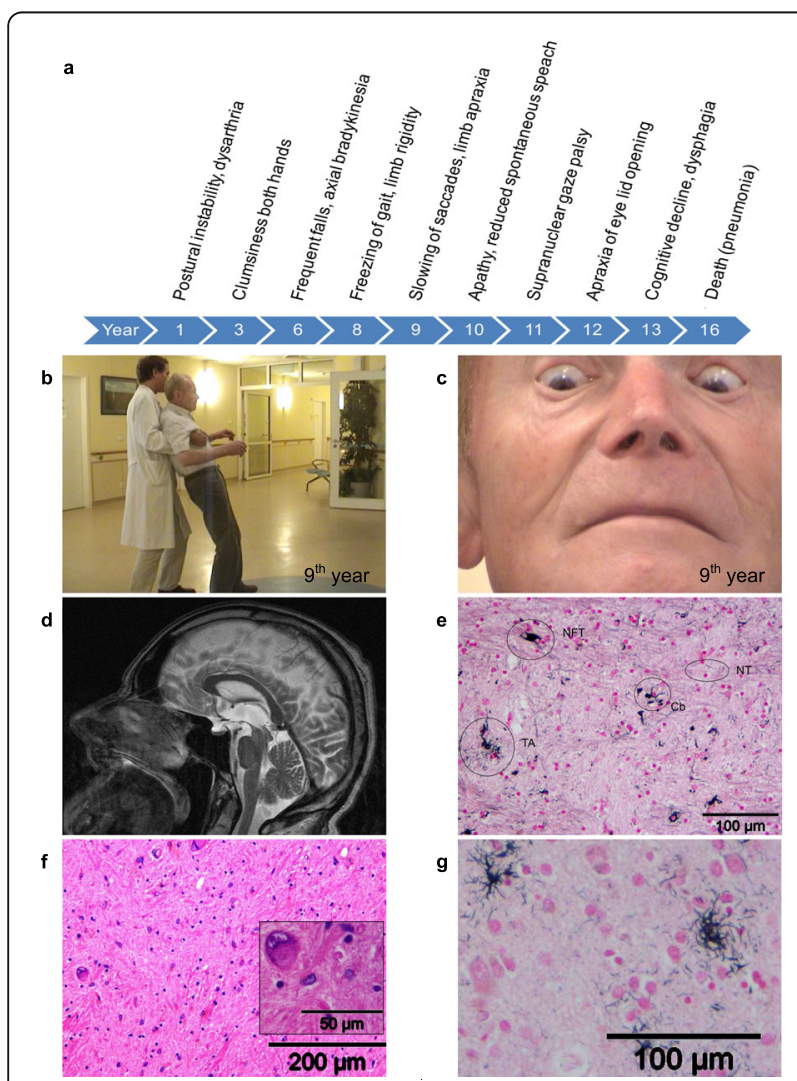

Fig. 1 Case presentation. a Timeline of the evolution of clinical symptoms. $\mathbf{b}$ and $\mathbf{c}$ Demonstration of absent supranuclear gaze palsy (SNGP) despite clear postural instability (PI) in the $9^{\text {th }}$ year after symptom onset. $\mathbf{d}$ MRI showing predominant midbrain atrophy in the $13^{\text {th }}$ year after symptom onset. e Representative histopathological section (pallidum) showing the typical histopathological hallmarks of PSP), i.e. tufted astrocytes (TA), coiled bodies (CB), neurofibrillary tangles (NFT) and neuropil threads (NT) (Gallyas silver stain). $\mathbf{f}$ Histopathological section (globus pallidus) with loss of neurons, intracytoplasmic inclusions and gliosis (Hematoxilin-Eosin staining). $\mathbf{g}$ Tufted astrocytes in striatum (globus pallidus) as the neuropathological hallmark of PSP (Gallyas silver stain) based and slowing of turning was noted, the patient did not require walking aids. The first falls occurred backwards in 2000, the patient had no gait ignition failure. At first, Parkinson's disease (PD) was suspected. After 5 years, atypical Parkinsonism was considered, since the patient showed frequent falls and was non-responsive to levodopa. The patient showed slight, but not pronounced micrographia and hypohonia in the beginning of the disease. Between year 5 and 10 after disease onset, the patient developed mild limb rigidity, symmetric bradykinesia, apraxia of both hands, freezing of gait and apathy. Slowing of vertical saccades despite full range of voluntary ocular movements in all directions was first observed in the $9^{\text {th }}$ year of his illness, vertical SNGP was only observed in the $11^{\text {th }}$ year (Fig. $1 \mathrm{~b}$ and c, Additional file 1). Apart from bilateral limb apraxia in the late course, the patient did not show other signs of cortical sensory loss. The patient's condition worsened due to dysphagia and cognitive decline in the $13^{\text {th }}$ year of the disease. The patient died of aspiration pneumonia after an exceptionally long disease duration of 15 years at the age of 82 .

\section{Brain imaging}

Single photon emission computed tomography (SPECT) with ${ }^{123}$ J-FP-CIT in the $8^{\text {th }}$ year revealed bilaterally reduced striatal dopamine transporter density. Magnetic resonance imaging (MRI) showed predominant atrophy of the midbrain tegmentum (anteroposterior midbrain diameter of $11.9 \mathrm{~mm}$ after 12 years and $11.6 \mathrm{~mm}$ after 14 years) with enlarged ventricular spaces, moderate prefrontal atrophy and discrete vascular lesions (Fig. 1d). The midbrain-to-pons-ratio was 0.49 [12].

\section{Autopsy findings}

Although the temporal evolution of symptoms was unusual, brain autopsy findings revealed typical neuropathological features of PSP: Macroscopically, slight frontotemporal and severe midbrain atrophy was observed, furthermore dilated lateral ventricles. While substantia nigra, dentate nucleus (cerebellum), locus coeruleus and medulla oblongata exhibited pronounced neurodegenerative changes (neuronal loss and gliosis) on haematoxylineosin-histology, globus pallidus showed only discrete neurodegenerative changes. Tau immunostaining demonstrated widespread tau deposits in tufted astrocytes (TA), coiled bodies (CB), neurofibrillary tangles (NFT) and neuropil threads (NT) in frontal cortex, striatum, insula, basal ganglia, amygdala, hippocampus, midbrain and pons. Thus, the neuropathologic criteria for PSP were clearly fulfilled (Fig. 1e) [2]. The tau distribution fits into score 45 according to the scale presented by Williams with more severe involvement of the basal ganglia and dentate nucleus with involvement of the frontal and parietal lobes [13]. Tufted astrocytes were mainly found in the caudate 
nucleus (severe) and frontal cortex (moderate) and transentorhinal cortex (moderate). The following concomitant neurodegenerative pathologies were observed: widespread beta amyloid deposits (stage 5) [14], cerebral amyloid angiopathy (1 type 2) [15], Alzheimer's disease (Braak and Braak stage 3) [16] and argyrophilic grain disease (stage 3) [17]. The "ABC" score for AD neuropathologic changes in this case was A3 B2 C2 [18]. TDP43 positive deposits were not detected in the following brain regions: frontal cortex, striatum, hippocampus and amygdala, caudal medulla and cerebellum.

\section{Conclusions}

While SNGP was initially described, and is still considered as the most specific clinical hallmark of PSP, coining the disease's name, we present to our knowledge the first prospectively video-documented and autopsyconfirmed PSP patient with an unexpected long latency of 11 years between the clinical disease onset with initially predominant PI and late development of SNGP. This patient provides clear evidence for the concept that a subgroup of definite PSP does indeed present with a clinical predominance type of PSP-PI [5]. We carefully considered the possibility of this case representing a variant of pure akinesia with gait freezing (PAGF), which is considered to be one of the phenotypic presentations of pallido-nigro-luysial atrophy (PNLA), a rare variant of PSP $[19,20]$. The long disease duration of 15 years and the late onset of SNGP fit the prior descriptions of PNLA/PSP-PAGF [20]. However, early onset of falls, late onset of freezing of gait and an advanced age at disease onset (67 years) compared to the previously reported PNLA/PSP-PAGF cases rendered this possibility unlikely [19]. Moreover, as mentioned above, this case clearly fulfilled the diagnostic criteria of PSP - high density of neurofibrillary tangles (NFT) and neuropil threads (NT) in three out of four cardinal nuclei: substantia nigra, globus pallidus and pons and a moderate-to-high density of NFT and NT three out of four of secondary areas (striatum, oculomotor complex and dentate nucleus of cerebellum) -and did not resemble the distribution of pathological changes in PNLA/PSP-PAGF $[2,11,19,20]$.

\section{Clinical differential diagnosis}

As hypokinesia in the left upper limb and hypomimia had initially been present, the diagnosis of PD had first been suggested. This diagnosis was questionable right from the beginning, since prominent PI was among the patient's initial complaints, which does not develop until late into the disease in typical PD. Furthermore, tremor, present in many patients with PD and some patients with PSP-P was absent in this patient throughout the clinical course. The clear lack of response to levodopa therapy despite evidence for presynaptic dopaminergic degeneration by SPECT imaging suggested postsynaptic dopaminoceptive dysfunction in this patient and affirmed the doubt at the diagnosis of PD $[9,21,22]$. There was no reason to suggest multiple system atrophy (MSA) because ataxia and autonomic dysfunction were absent $[9,22]$. A corticobasal syndrome (CBS) might have been considered by year 9 , since apraxic features occurred in both hands. However, neither dystonia, myoclonus, nor alien limb phenomenon as additional cortical features were present, the motor signs were strikingly symmetric by then, and the average survival time of CBS patient (7.9 years) had passed by far at this time, rendering the diagnosis of CBS unlikely $[9,21,23]$. Brain imaging did not show vascular lesions of the basal ganglia and brainstem suggestive of vascular parkinsonism. Slowing of vertical saccades allowed the diagnosis of possible PSP according to the NINDS-SPSP criteria in the $9^{\text {th }}$ year of his illness. With development of vertical SNGP, the patient fulfilled the criteria for probable PSP in the $11^{\text {th }}$ year [5]. Cognitive changes typically observed in PSP, including apathy and reduced verbal fluency were not observed until 10 years after onset in this patient [21, 24]. Predominant mesencephalic atrophy clearly below the threshold suggestive of PSP [25] has been demonstrated by MRI in the $12^{\text {th }}$ year Since data from prior MRI is not available, it cannot be verified if structural imaging had allowed to suggest PSP at an earlier time point than the clinical features. As typical for PSP, the patient developed dysphagia in the terminal phase and died of aspiration pneumonia. Compared to the average disease duration of PSP (8.7 years) [10], the patient experienced an exceptionally long disease duration of 15 years, but individual cases with survival as long as 16 years have been previously reported [3].

In summary, this clinically well documented case strengthens the concept that individual patients with definite PSP can present with predominant progressive PI (PSP-PI predominance type), as it had been previously proposed on the basis of a retrospective case series. This observation further expands the clinical spectrum of definite PSP and underlines the need to adapt the clinical diagnostic criteria to allow diagnosing syndromes suggestive for PSP, such as PSP-PI, as early as possible.

\section{Additional file}

Additional file 1: Video-documented clinical course of an autopsyconfirmed PSP patient with predominant postural instability (PSP-PI) and very late onset of ocular motor dysfunction. In 1997, the initial symptoms occurred at the age of 67. The patient was filmed three times. In 2005 ( $9^{\text {th }}$ year after onset) postural instability and freezing of gait was observed. In 2006 (10 th year after onset) gait became further unstable despite full range of voluntary ocular movements. In 2009 (13 ${ }^{\text {th }}$ year after onset) the patient showed supranuclear gaze palsy, apraxia of eye-lid opening and cognitive decline. (MP4 $12617 \mathrm{~kb}$ ) 


\section{Abbreviations}

CB: Coiled bodies; CBS: Corticobasal syndrome; FTD: Frontotemporal dysfunction; MRI: Magnetic resonance imaging; MSA: Multisystem atrophy; NFT: Neurofibrillary tangles; NT: Neuropil threads; PAGF: Pure akinesia with gait freezing; PD: Parkinson's disease; PI: Postural instability; PNFA: Pallidonigro-luysial atrophy; PSP: Progressive supranuclear palsy; PSP-PI: PSP with predominating postural instability; TA: Tufted astrocytes

\section{Acknowledgments}

We thank the patient's family for supplying us with information and the informed consent for publication, Sigrun Roeber for the conduction of the histopathological stainings, the neuropathological classification and the histopathological images. We would like to thank Brigitte Kraft for excellent technical assistance. Günter Höglinger was supported by the Deutsche Forschungsgemeinschaft (DFG, HO2402/6-2).

\section{Funding}

GUH was funded by the Deutsche Forschungsgemeinschaft (DFG, HO2402/6-2). The cost of the study was covered by internal funds of the Center for Neuropathology and Prion Research and DZNE Munich.

\section{Availability of data and materials}

Not applicable, no datasets were generated for this manuscript.

\section{Authors' contributions}

CK and GUH compiled the conception and the organization of the research project; GE contributed videos, MRI and clinical records; TA, AG and CK conducted the neuropathological examinations; CK, GE, GR and GUH drafted the manuscript; all authors reviewed the manuscript. All authors read and approved the final manuscript.

\section{Competing interests}

The authors declare that they have no competing interests.

\section{Consent for publication}

Consent for the use of the brain tissue and medical records for research purposes and for publication was obtained from the patient's next of kin.

\section{Ethics approval and consent to participate}

The study has been approved by the local ethics committee of the medical faculty of the Ludwigs-Maximilians-Universität München.

\section{Author details}

${ }^{1}$ Psychiatric Clinic, Psychiatrische Klinik, Ludwigs-Maximilians-Universität München, Nußbaumstr. 7, 80336 Munich, Germany. ${ }^{2}$ Hospital for Movement Disorders and Parkinson's Disease, Straße nach Fichtenwalde 16, 14547 Beelitz-Heilstätten, Germany. ${ }^{3}$ Department of Neurology, Technische Universität München, Ismaningerstr. 22, 81675 Munich, Germany. ${ }^{4}$ German Center for Neurodegenerative Diseases e.V. (DZNE) Munich, Feodor-Lynen Str. 17, 81377 Munich, Germany. ${ }^{5}$ Center for Neuropathology and Prion Research, Ludwig-Maximilians-University Munich, Feodor-Lynen-Str. 22, 81377 Munich, Germany.

Received: 27 September 2016 Accepted: 29 October 2016 Published online: 14 November 2016

\section{References}

1. Dickson DW, Ahmed Z, Algom AA, Tsuboi Y, Josephs KA. Neuropathology of variants of progressive supranuclear palsy. Curr Opin Neurobiol. 2010;23: 394-400. doi:10.1097/WCO.0b013e32833be924.

2. Hauw JJ, Daniel SE, Dickson D, Horoupian DS, Jellinger K, Lantos PL, McKee A, Tabaton M, Litvan I. Preliminary NINDS neuropathologic criteria for Steele-Richardson-Olszewski syndrome (progressive supranuclear palsy). Neurology. 1994:44:2015-9.

3. Litvan I, Mangone CA, McKee A, Verny M, Parsa A, Jellinger K, D'Olhaberriague L, Chaudhuri KR, Pearce RK. Natural history of progressive supranuclear palsy (Steele-Richardson-Olszewski syndrome) and clinical predictors of survival: a clinicopathological study. J Neurol Neurosurg Psychiatry. 1996;60:615-20.
4. Williams DR, Lees AJ. Progressive supranuclear palsy: clinicopathological concepts and diagnostic challenges. Lancet Neurol. 2009;8:270-9. doi:10. 1016/S1474-4422(09)70042-0.

5. Litvan I, Agid Y, Calne D, Campbell G, Dubois B, Duvoisin RC, Goetz CG, Golbe LI, Grafman J, Growdon JH, et al. Clinical research criteria for the diagnosis of progressive supranuclear palsy (Steele-Richardson-Olszewski syndrome): report of the NINDS-SPSP international workshop. Neurology. 1996:47:1-9.

6. Williams DR, de Silva R, Paviour DC, Pittman A, Watt HC, Kilford L, Holton JL, Revesz T, Lees AJ. Characteristics of two distinct clinical phenotypes in pathologically proven progressive supranuclear palsy: Richardson's syndrome and PSP-parkinsonism. Brain. 2005;128:1247-58. doi:10.1093/ brain/awh488.

7. Davis PH, Bergeron C, McLachlan DR. Atypical presentation of progressive supranuclear palsy. Ann Neurol. 1985:17:337-43. doi:10.1002/ana.410170406.

8. Daniel SE, de Bruin VM, Lees AJ. The clinical and pathological spectrum of Steele-Richardson-Olszewski syndrome (progressive supranuclear palsy): a reappraisal. Brain. 1995;118(Pt 3):759-70.

9. Litvan I, Grimes DA, Lang AE, Jankovic J, McKee A, Verny M, Jellinger K, Chaudhuri KR, Pearce RK. Clinical features differentiating patients with postmortem confirmed progressive supranuclear palsy and corticobasal degeneration. J Neurol. 1999;246 Suppl 2:I11-5.

10. Respondek G, Stamelou M, Kurz C, Ferguson LW, Rajput A, Chiu WZ, van Swieten JC, Troakes C, Al Sarraj S, Gelpi E, et al. The phenotypic spectrum of progressive supranuclear palsy: a retrospective multicenter study of 100 definite cases. Mov Disord. 2014;29:1758-66. doi:10.1002/mds.26054.

11. Litvan I, Hauw JJ, Bartko JJ, Lantos PL, Daniel SE, Horoupian DS, McKee A, Dickson D, Bancher C, Tabaton M. Validity and reliability of the preliminary NINDS neuropathologic criteria for progressive supranuclear palsy and related disorders. J Neuropathol Exp Neurol. 1996;55:97-105.

12. Massey LA, Jager HR, Paviour DC, O'Sullivan SS, Ling H, Williams DR, Kallis C, Holton J, Revesz T, Burn DJ, et al. The midbrain to pons ratio: a simple and specific MRI sign of progressive supranuclear palsy. Neurology. 2013;80: 1856-61. doi:10.1212MNL.0b013e318292a2d2.

13. Williams DR, Holton JL, Strand C, Pittman A, de Silva R, Lees AJ, Revesz T. Pathological tau burden and distribution distinguishes progressive supranuclear palsy-parkinsonism from Richardson's syndrome. Brain. 2007; 130:1566-76. doi:10.1093/brain/awm104.

14. Thal DR, Rub U, Orantes M, Braak H. Phases of A -deposition in the human brain and its relevance for the development of AD. Neurology. 2002;58: 1791-800. doi:10.1212/wnl.58.12.1791.

15. Thal DR, Griffin WS, de Vos RA, Ghebremedhin E. Cerebral amyloid angiopathy and its relationship to Alzheimer's disease. Acta Neuropathol. 2008;115:599-609. doi:10.1007/s00401-008-0366-2.

16. Braak H, Alafuzoff I, Arzberger T, Kretzschmar H, Del Tredici K. Staging of Alzheimer disease-associated neurofibrillary pathology using paraffin sections and immunocytochemistry. Acta Neuropathol. 2006;112:389-404. doi:10.1007/s00401-006-0127-z.

17. Saito Y, Ruberu NN, Sawabe M, Arai T, Tanaka N, Kakuta Y, Yamanouchi H, Murayama S. Staging of argyrophilic grains: an age-associated tauopathy. J Neuropathol Exp Neurol. 2004;63:911-8.

18. Montine TJ, Phelps CH, Beach TG, Bigio EH, Cairns NJ, Dickson DW, Duyckaerts C, Frosch MP, Masliah E, Mirra SS, et al. National Institute on Aging-Alzheimer's Association guidelines for the neuropathologic assessment of Alzheimer's disease: a practical approach. Acta Neuropathol. 2012;123:1-11. doi:10.1007/s00401-011-0910-3.

19. Ahmed Z, Josephs KA, Gonzalez J, DelleDonne A, Dickson DW. Clinical and neuropathologic features of progressive supranuclear palsy with severe pallido-nigro-luysial degeneration and axonal dystrophy. Brain. 2008;131: 460-72. doi:10.1093/brain/awm301.

20. Williams DR, Holton JL, Strand K, Revesz T, Lees AJ. Pure akinesia with gait freezing: a third clinical phenotype of progressive supranuclear palsy. Mov Disord. 2007;22:2235-41. doi:10.1002/mds.21698.

21. Christine CW, Aminoff MJ. Clinical differentiation of parkinsonian syndromes: prognostic and therapeutic relevance. Am J Med. 2004;117:412-9. doi:10. 1016/j.amjmed.2004.03.032.

22. Liscic RM, Srulijes K, Groger A, Maetzler W, Berg D. Differentiation of progressive supranuclear palsy: clinical, imaging and laboratory tools. Acta Neurol Scand. 2013;127:362-70. doi:10.1111/ane.12067.

23. Mahapatra RK, Edwards MJ, Schott JM, Bhatia KP. Corticobasal degeneration. Lancet Neurol. 2004;3:736-43. doi:10.1016/S1474-4422(04)00936-6. 
24. Soliveri P, Monza D, Paridi D, Carella F, Genitrini S, Testa D, Girotti F. Neuropsychological follow up in patients with Parkinson's disease, striatonigral degeneration-type multisystem atrophy, and progressive supranuclear palsy. J Neurol Neurosurg Psychiatry. 2000;69:313-8.

25. Warmuth-Metz M, Naumann M, Csoti I, Solymosi L. Measurement of the midbrain diameter on routine magnetic resonance imaging: a simple and accurate method of differentiating between Parkinson disease and progressive supranuclear palsy. Arch Neurol. 2001;58:1076-9.

Submit your next manuscript to BioMed Central and we will help you at every step:

- We accept pre-submission inquiries

- Our selector tool helps you to find the most relevant journal

- We provide round the clock customer support

- Convenient online submission

- Thorough peer review

- Inclusion in PubMed and all major indexing services

- Maximum visibility for your research

Submit your manuscript at www.biomedcentral.com/submit 